\title{
Open water, inundated vegetation and upland vegetation discriminated through a disturbing atmosphere
}

\author{
U. Böttger ${ }^{1}$, A. Demircan ${ }^{2}$, and V. Vanderbilt ${ }^{3}$ \\ ${ }^{1}$ DLR, Institut für Planetenforschung, Berlin, Germany \\ ${ }^{2}$ Deutsches Patent- und Markenamt, Ref. 2.5.1, Zweibrückenstr. 5-7, 80297 München, Germany \\ ${ }^{3}$ NASA Ames Research Center, Moffett Field, CA 94035, USA
}

\begin{abstract}
Methane is an important greenhouse gas. The areal extent of Boreal wetlands, source areas for methane, is poorly known. At times estimates have differed by as much as seven fold, which contributes uncertainty to present day energy and carbon budgets and to projections of future climates.

In this research we applied optical remote sensing technology to identify methane source areas in POLDER imagery collected from both aircraft and satellite. Our approach takes advantage of the specular reflecting properties of surface waters in order to differentiate inundated wetlands (with emergent vegetation), open water (without emergent vegetation) and non-inundated cover types.

Unlike our previous research, here we account for the affects of the disturbing atmosphere, presenting a radiative transfer model that represents an atmosphere above a mixed pixel that includes various proportions of open water, inundated vegetation and upland vegetation. The results show that our algorithm accurately identified these three cover types in both aircraft and satellite data. The results point to the probable importance of atmospheric correction to the discrimination procedure.
\end{abstract}

\section{Introduction}

Methane is an important greenhouse gas (Schiermeier, 2005). The areal extent of Boreal wetlands, source areas for methane $\left(\mathrm{CH}_{4}\right)$, is poorly known (Klinger et al., 1994; Bartlett and Harriss, 1993; Roulet et al., 1992; Moore and Knowles, 1990; Crill et al., 1988). Estimates have differed nearly seven fold (Aselmann and Crutzen, 1989), which contributes uncertainty to present day energy and carbon budgets and to projections of future climates. In the case of boreal

Correspondence to: U. Böttger

(ute.boettger@dlr.de) ecosystems, remote sensing technology provides the only practical means to monitor wetland condition and areal extent. When mapping these methane source areas, researchers in optical remote sensing have exploited the differing specular reflecting properties of inundated wetlands (bogs and fens - areas with emergent vegetation and high $\mathrm{CH}_{4}$ exchange rates), open water (lakes and ponds - areas with low $\mathrm{CH}_{4}$ exchange rates and no emergent vegetation) and non-inundated cover types (Morrissey and Livingston, 1992). The often visually blinding specular reflection of sunlight from surface waters provides a strong, angular signature reflection characteristic of inundated, $\mathrm{CH}_{4}$-producing areas and uncharacteristic of non-inundated, non- $\mathrm{CH}_{4}$-producing cover types (Morrissey and Livingston, 1992). Furthermore, inundated wetlands and open water areas, the key $\mathrm{CH}_{4}$-producing areas, display different, wind dependent glitter signatures as a function of view angle (Vanderbilt et al., 2002). Thus, analysis of remotely sensed data, collected in and near the specular direction, has allowed accurate discrimination and mapping of these three cover types. However, the prior research did not correct the remotely sensed data for the disturbing effects of the atmosphere. Here we present a new algorithm for discriminating these three cover types. We apply this discrimination algorithm, which includes parameters derived from an atmospheric correction algorithm, to identify these three cover types in both aircraft and satellite POLDER data.

\section{Methods}

\subsection{Data collection}

Data were collected using aircraft POLDER, a large fieldof-view, multispectral, imaging sensor (Breon et al., 1997; Leroy and Breon, 1996) within the BOREAS Southern Study Area (SSA), in central Canada $\left(54^{\circ} \mathrm{N}, 105^{\circ} \mathrm{W}\right)$ near Prince Albert, Saskatchewan. The radiance imagery was acquired

Published by Copernicus Publications on behalf of the URSI Landesausschuss in der Bundesrepublik Deutschland e.V. 
Table 1. Data collection dates summer 1994.

\begin{tabular}{lccccc}
\hline Test site & 26 May & 31 May & 1 June & 21 July & 24 July \\
\hline Old Aspen & $\mathrm{x}$ & $\mathrm{x}$ & & & \\
Old Black Spruce & & $\mathrm{x}$ & & $\mathrm{x}$ & \\
Young Jack Pine & & & $\mathrm{x}$ & $\mathrm{x}$ & \\
Old Jack Pine & & $\mathrm{x}$ & $\mathrm{x}$ & $\mathrm{x}$ & $\mathrm{x}$ \\
Fen & & & & & $\mathrm{x}$ \\
\hline
\end{tabular}

Table 2. Data collection dates December/January 1996/97.

\begin{tabular}{lccccc}
\hline Date & latitude & longitude & Date & latitude & longitude \\
\hline 12 Dec & 22.6389 & 83.7692 & 15 Dec & 20.0833 & 80.6540 \\
21 Dec & 20.1389 & 96.4201 & 21 Dec & 18.9722 & 95.4928 \\
29 Dec & 22.7500 & 100.2108 & 01 Jan & 16.7500 & 102.7038 \\
09 Jan & 19.5278 & 98.7525 & 13 Jan & 22.3056 & 100.9573 \\
16 Jan & 19.5833 & 95.4242 & 17 Jan & 20.7500 & 102.9208 \\
19 Jan & 22.6944 & 91.7464 & 25 Jan & 16.4167 & 79.7780 \\
31 Jan & 22.1389 & 96.5378 & 23 Dec & 5.8055 & -71.1232 \\
27 Dec & 7.0833 & -68.8367 & 15 Jan & 9.5833 & -65.7183 \\
20 Jan & 4.6944 & -58.3369 & 23 Jan & 6.1944 & -62.7290 \\
05 Dec & 17.9722 & 87.3426 & 13 Dec & 12.4722 & 90.1991 \\
16 Dec & 18.1389 & 86.5508 & 17 Dec & 18.4167 & 93.9525 \\
17 Dec & 17.3056 & 93.2590 & 27 Dec & 14.0278 & 84.6739 \\
03 Jan & 14.6944 & 81.9304 & 15 Jan & 11.8611 & 86.7077 \\
19 Jan & 19.6944 & 90.6197 & 19 Jan & 16.5833 & 89.3623 \\
22 Jan & 13.4722 & 84.0019 & 22 Jan & 9.4722 & 82.9318 \\
24 Jan & 14.2500 & 97.3089 & 28 Jan & 9.4722 & 98.1383 \\
29 Jan & 15.3611 & 81.5013 & 26 Jan & 10.3055 & -41.5276 \\
\hline
\end{tabular}

over five test sites on several dates, Table 1, at an altitude of $5 \mathrm{~km}$. Images are $384 \times 288$ pixels with an apparent ground resolution of $35 \mathrm{~m} \times 35 \mathrm{~m}$. Surface wind speeds were measured at the Old Jack Pine test site, located within $15 \mathrm{~km}$ of the various flight lines (Shewchuk, 1997). Wide angle, large format, color infrared aerial photographs $(23 \mathrm{~cm} \times 23 \mathrm{~cm})$ that included the subsolar or specular direction were collected concurrently from the C-130 aircraft. The POLDER data and other data from the Boreas experiment are available through the User Services Office of the Oak Ridge National Laboratory Distributed Active Archive Center (ORNL DAAC), Oakridge, Tennessee, USA.

Satellite POLDER data (Deschamps et al., 1994), collected during late December of 1996 and early January 1997 and processed and available from the French Space Agency CNES (http://smsc.cnes.fr/POLDER/) to level 1b (imagery) and level 2 (optical thickness), were obtained for 18 land areas located away from larger cities in and 16 open ocean areas adjacent to India, Thailand, Myanmar and Brazil, Table 2. Photo-interpretation of the land imagery suggested two of the 18 land areas contain wetlands and the remaining areas are vegetated upland areas.

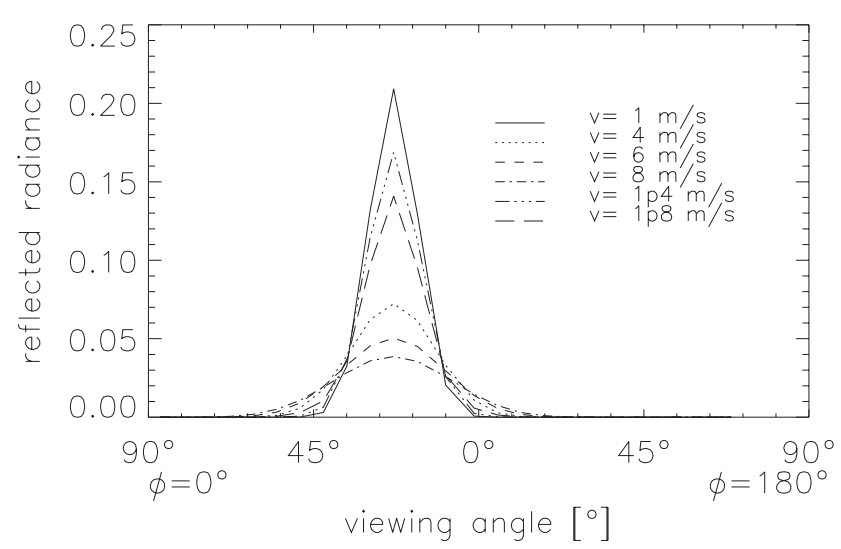

Fig. 1. Reflection function of a wind driven water surface for surface wind speeds of $1 \mathrm{~m} / \mathrm{s}, 4 \mathrm{~m} / \mathrm{s}, 6 \mathrm{~m} / \mathrm{s}$ and $8 \mathrm{~m} / \mathrm{s}$. The sun incident angle is $22^{\circ}$.

\subsection{Atmospheric correction}

A ground area was selected for analysis only if its relative radiance $R_{\text {meas }}\left(\lambda_{1,2,3}, \mu_{0,1,2}, \tau\right)$ was measured by POLDER in three sun/view directions: the subsolar direction $\pm 2^{\circ}$ (also called the specular or sun glint direction), $7^{\circ} \pm 1^{\circ}$ and $14^{\circ} \pm 1^{\circ}$ away from the specular direction towards the nadir view direction and away from the subsolar direction. For analysis purposes these three directions are represented by the cosine of the view zenith angle, $\mu$, and labelled, $\mu_{0}$ to $\mu_{2}$, according to the increasing directional distance from the subsolar direction. The aerosol optical thicknesses $\tau$ at the three wavelengths $\lambda_{1,2,3}$ were obtained as a POLDER level 2 product from CNES. We established a lookup table of correction factors $f\left(\tau_{\text {lookup }}, \lambda, \mu, v\right)$ derived from radiative transfer calculations with the radiative transfer simulation program STORM (Böttger and Preusker, 2006) for an atmospherewater surface system:

$f\left(\tau_{\text {lookup }}, \lambda, \mu_{i}, v\right)=\frac{T O A\left(\tau_{\text {lookup }}, \lambda, \mu_{i}, v\right)}{R_{\text {Surf }}\left(\lambda, \mu_{i}, v\right)}$

where $\quad\left(T O A\left(\tau_{\text {lookup }}, \lambda, \mu_{i}, v\right), i=0,2\right) \quad$ is $\quad$ the calculated reflectance at the top of atmosphere and $R_{\text {Surf }}\left(\left(\lambda, \mu_{i}, v\right), i=0,2\right)$, the calculated reflectance directly above a wind driven water surface of wind speed $v$ without any atmospheric contribution. The values $R_{\text {Surf }}\left(\lambda, \mu_{i}, v\right)$ are calculated for six surface wind conditions - wind speeds of $1 \mathrm{~m} / \mathrm{s}, 4 \mathrm{~m} / \mathrm{s}, 6 \mathrm{~m} / \mathrm{s}, 8 \mathrm{~m} / \mathrm{s}$ and also mixtures of a $1 \mathrm{~m} / \mathrm{s}$ with $4 \mathrm{~m} / \mathrm{s}$ and $8 \mathrm{~m} / \mathrm{s}$ - using Fresnel's law and a semi empirical model of the normal distribution of a wind ruffled water surface (Cox and Munk, 1954), Fig. 1. Values of $R_{\text {Surf }}\left(\lambda, \mu_{i}, v\right)$ are assumed to be wavelength independent; thus $R_{\text {Surf }}\left(\lambda_{1}, \mu_{i}, v\right)=R_{\text {Surf }}\left(\lambda_{2}, \mu_{i}, v\right)=R_{\text {Surf }}\left(\lambda_{3}, \mu_{i}, v\right)$ and the ratio $R_{\text {Surf }}\left(\lambda, \mu_{i}, v\right) / R_{\text {Surf }}\left(\lambda, \mu_{j}, v\right)$ is wavelength independent. Values of $\operatorname{TOA}\left(\tau_{\text {lookup }}, \lambda, \mu_{i}, v\right)$ were calculated as a function of $R_{\operatorname{Surf}}(\lambda, \mu, v)$, aerosol optical thickness and aerosol type. Correction factors corresponding 


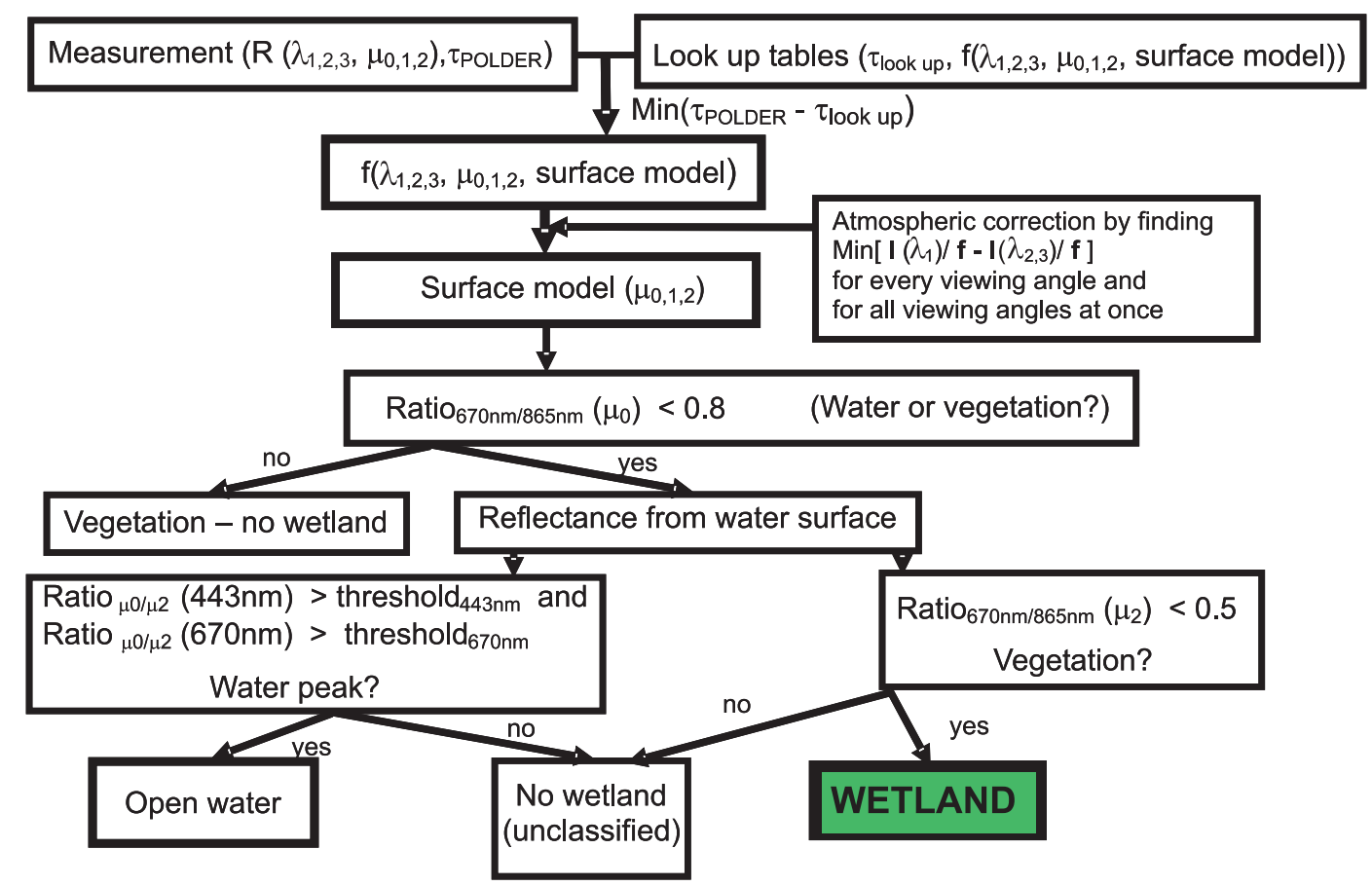

Fig. 2. Principle scheme for discrimination of wetlands from non-inundated surfaces and open water.

to the measurements $R_{\text {meas }}(\tau, \lambda, \mu)$ were calculated with reference to the lookup table by minimizing the difference between $\tau$ and $\tau_{\text {lookup. }}$ While the effects of only non- or weakly absorbing aerosols and only five wind speed conditions are reported here, more strongly absorbing aerosols and larger wind speeds may easily be incorporated in future applications of this model.

At each view angle and wavelength the atmospheric correction, the ratio of the measured reflectance and the correction factor $R_{\text {meas }}\left(\mu_{i}, \ldots\right) / f\left(\mu_{i}, \ldots\right) \rightarrow R_{\text {Surf }}\left(R_{\text {meas }}\left(\mu_{i}, v\right)\right)$, provides a set of surface reflectances $R_{\text {Surf }}\left(R_{\text {meas }}\left(\mu_{i}, v\right)\right)$ that correspond to the five wind dependent surface reflection models. Finally, the most suitable of the six surface reflection models is selected such that the wavelength dependence of $R_{\text {Surf }}\left(R_{\text {meas }}\left(\mu_{i}, v\right)\right)$ is minimized.

\subsection{Synthetic data}

For developing and testing our discrimination algorithm, we created a synthetic data set that included

a) a wind-ruffled open water surface,

b) a mixture of two water models $(1 \mathrm{~m} / \mathrm{s}$ and $4 \mathrm{~m} / \mathrm{s}$ or $8 \mathrm{~m} / \mathrm{s}$ ) to simulate wetlands,

c) a Lambertian surface with wavelength independent albedo,

d) a Lambertian surface simulating sand (albedo: $\left.a_{443 \mathrm{~nm}}=0.01, a_{670 \mathrm{~nm}}=0.05, a_{865 \mathrm{~nm}}=0.05\right)$ and

e) a Lambertian surface simulating vegetation (albedo: $\left.a_{443 \mathrm{~nm}}=0.01, a_{670 \mathrm{~nm}}=0.05, a_{865 \mathrm{~nm}}=0.5\right)$.

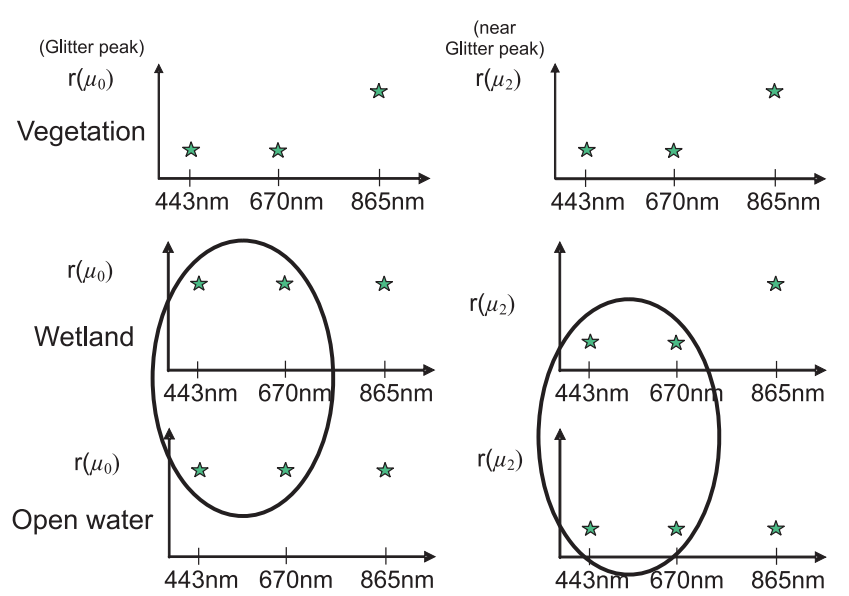

Fig. 3. Discrimination thresholds: principle differences in the spectral and angular behaviour of different surfaces. The upper pair of graphs shows schematically the spectral behaviour of reflected light at the sun glint angle (left) and the angle $14^{\circ}$ apart toward nadir (right) for vegetation. The middle pair and the lower pair of graphs show the same for wetland and open water, respectively.

\subsection{Discrimination procedure}

The discrimination procedure, Figs. 2 and 3, involves four steps: first, we decided a pixel contained vegetation and no 


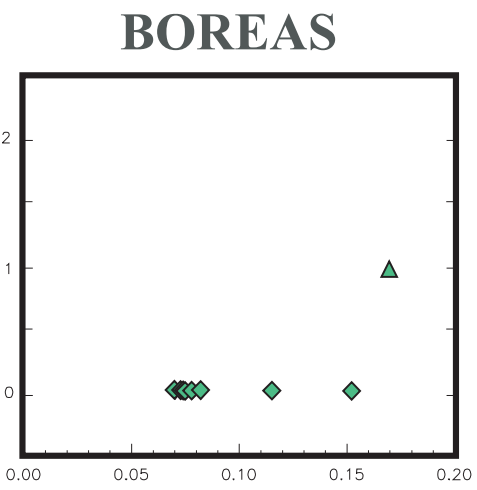

Fig. 4. Boreas and satellite Polder results.

surface water if both

$$
\begin{aligned}
& \operatorname{Ratio}_{670 \mathrm{~nm} / 865 \mathrm{~nm}}\left(\mu_{0}\right)= \\
& R_{\operatorname{Surf}}\left(\mu_{0}, 670 \mathrm{~nm}\right) / \mathrm{R}_{\text {Surf }}\left(\mu_{0}, 865 \mathrm{~nm}\right)<0.8 \\
& \operatorname{Ratio}_{670 \mathrm{~nm} / 865 \mathrm{~nm}}\left(\mu_{2}\right)= \\
& R_{\text {Surf }}\left(\mu_{2}, 670 \mathrm{~nm}\right) / \mathrm{R}_{\text {Surf }}\left(\mu_{2}, 865 \mathrm{~nm}\right)<\alpha_{1}
\end{aligned}
$$

Second, we decided a pixel contained inundated vegetation if both

$$
\begin{aligned}
& \text { Ratio }_{\mu_{0} / \mu_{2}}(443 \mathrm{~nm})= \\
& R_{\text {Surf }}\left(\mu_{0}, 443 \mathrm{~nm}\right) / \mathrm{R}_{\text {Surf }}\left(\mu_{2}, 443 \mathrm{~nm}\right)>\alpha_{2} \\
& \operatorname{Ratio}_{\mu_{0} / \mu_{2}}(670 \mathrm{~nm})= \\
& R_{\text {Surf }}\left(\mu_{0}, 670 \mathrm{~nm}\right) / \mathrm{R}_{\text {Surf }}\left(\mu_{2}, 670 \mathrm{~nm}\right)>\alpha_{2}
\end{aligned}
$$

Third, if Eqs. (2-3) are not true, then we decided the pixel contained open water if

$$
\begin{aligned}
& \text { Ratio }_{670 \mathrm{~nm} / 865 \mathrm{~nm}}\left(\mu_{2}\right)>0.5 \\
& \operatorname{Ratio}_{\mu_{0} / \mu_{2}}(443 \mathrm{~nm}) \quad>\quad \alpha_{3} \\
& \text { Ratio }_{\mu_{0} / \mu_{2}}(670 \mathrm{~nm})>\alpha_{3}
\end{aligned}
$$

Finally, if Eq. (4) is not true, then we decided the pixel included vegetation and no surface water. The thresholds, $\alpha_{1,2,3}$, necessary for wetland discrimination were established with reference to the discrimination process applied to the synthetic data using the atmospheric correction factors for a wind speed of $6 \mathrm{~m} / \mathrm{s}$ and the smallest aerosol optical thickness. We repeated this discrimination procedure, Eqs. (2-4), using atmospherically corrected surface reflection values in order to understand the influence of the atmosphere.

\section{Results and discussion}

From analysis of 11 aircraft POLDER pixels, selected according to the directional criteria (see Methods), one pixel was correctly identified by the discrimination algorithm, Fig. 4 (left), as representing inundated vegetation $-\mathrm{a}$ fen and 10 pixels were correctly identified as representing upland vegetation, demonstrating that our discrimination procedure provides good results. Because the atmospheric aerosol concentrations during aircraft data collection were essentially zero, application of the atmospheric correction procedures had no affect upon the results. Of the 34 satellite POLDER pixels meeting the directional criteria, 16 were correctly identified by the discrimination algorithm, Fig. 4 (right), as representing open water areas, in this case open ocean. Unlike for the 11 aircraft pixels and the 16 open ocean pixels, the results for the 18 land pixels are based primarily upon photo-interpretation and only regional-level ground truth data and thus are more difficult to verify. After atmospheric correction, two of the 18 land pixels were correctly identified - based upon the results of photo-interpretation - as inundated vegetation, while the remainder were correctly identified as upland vegetation. However, without atmospheric correction, only one of the two inundated vegetation areas was correctly identified, while the remaining 17 areas were identified as upland vegetation, thereby underscoring the probable importance of atmospheric correction to the wetland discrimination procedure. Cover types in the 18 land areas included tropical rain forest, brushlands and agricultural crops - including rice fields that would be seasonally inundated during acquisition of these these late December 1996 and early January 1997 POLDER images.

In this research we discriminated inundated plant communities, open water areas and non-inundated (upland) areas with reference to a model of the reflectance of surface waters, noting that high radiance values measured in and near the subsolar direction signals the presence of surface water (either open water or inundated plant communities), in contrast to dry upland plant communities. Our discrimination procedure, Fig. 2, extends the approach in (Vanderbilt et al., 2002) to include correction for the disturbing effects of the atmosphere. Here we take advantage of the result (Vanderbilt et al., 2002) that a light-to-moderate wind ruffles open water areas but does not ruffle surface waters sheltered by emergent vegetation, which allows us to discriminate the BRDF signatures for these two cover types. The ruffled surface of open water areas specularly reflects light into a broad range of directions and, therefore, appears bright in view directions 
both near and far from the subsolar view direction. The relatively flat, unruffled water surface underlying the sheltering inundated vegetation specularly reflects the incident sunlight into a narrow pencil of directions, Fig. 1. When compared with these two surface water cover types, upland exhibits small radiance values in all view directions. Our discrimination approach depends upon a ratio of two atmospherically corrected surface reflectances, one for the subsolar direction and the other $\mu_{2}=14^{\circ}$ away from the subsolar direction, $R_{\text {Surf }}\left(R_{\text {meas }}\left(\mu_{0}, v\right)\right) / R_{\text {Surf }}\left(R_{\text {meas }}\left(\mu_{2}, v\right)\right)$, a direction selected through application of the discrimination algorithm, Fig. 3, to the synthetic data set.

\section{Conclusions}

These results provide a wetlands discrimination procedure that includes correction for the disturbing affects of the atmosphere. The results point to the probable importance of atmospheric correction to that discrimination procedure.

\section{References}

Aselmann, I. and Crutzen, P. J.: Global distribution of natural freshwater wetlands and rice paddies, their net primary productivity, seasonality and possible methane emissions, J. Atmos. Chem., 8, 307-358, 1989.

Bartlett, K. and Harriss, R.: Review and assessment of methane emissions from wetlands, Chemosphere, 26, 261-320, 1993.

Böttger, U. and Preusker, R.: Radiative transfer model STORM for full Stokes vector calculations in the visible and near infrared spectral range, Adv. Radio Sci., 4, 329-335, 2006, http://www.adv-radio-sci.net/4/329/2006/.

Breon, F., Vanderbilt, V., Leroy, M., Bicheron, P., Walthall, C., and Kalshoven, J.: Evidence of hot spot directional signature from airborne POLDER measurements, IEEE Transactions on Geoscience and Remote Sensing, 35, 479-484, 1997.
Cox, C. and Munk, W.: Measurements of the roughness of the Sea Surface from Photographs of the Sun's Glitter, J. Opt. Soc. Am., 44, 838-850, 1954.

Crill, P., Bartlett, K., Harriss, R., Gorham, E., and Verry, E.: Methane flux from Minnesota peatlands, Global Biogeochem. Cycles, 2(4), 371-384, 1988.

Deschamps, P., Breon, F., Leroy, M., Podaire, A., Bricaud, A., Buriez, J., and Seze, G.: The POLDER mission: Instrument characteristics and scientific objectives, IEEE Transactions on Geoscience and Remote Sensing, 32, 598-615, 1994.

Klinger, L. F., Zimmerman, P. R., Greenberg, J. P., Heidt, L. E., and Guenther, A. B.: Carbon trace gas fluxes along a successional gradient in the Hudson Bay lowland, J. Geophys. Res., 99, 14691494, 1994.

Leroy, M. and Breon, F.: Surface reflectance angular signatures from airborne POLDER data, Remote Sensing of Environment, 57, 97-107, 1996.

Moore, T. R. and Knowles, R.: Methane emissions from fen, bog and swamp peatlands in Quebec, Biogeochemistry, 11(1), 1-76, 1990.

Morrissey, L. A. and Livingston, G. P.: Methane emissions from Alaska Arctic tundra: an assessment of local spatial variability, J. Geophys. Res., 97, 16 661-16670, 1992.

Roulet, N. T., Ash, R., and Moore, T. R.: Low boreal wetlands as a source of atmospheric methane, J. Geophys. Res., 97, 37393749, 1992.

Schiermeier, Q.: Climate change: That sinking feeling, Nature, 435, 732-733, 2005.

Shewchuk, S. R.: Surface Mesonet for BOREAS, J. Geophys. Res., 102, 29077-29082, 1997.

Vanderbilt, V., Perry, G., Livingston, G., Ustin, S., Barrios, M. D., Bréon, F., Leroy, M., Balois, J., Morrissey, L., Shewchuk, S., Stearn, J., Zedler, S., Syder, J. L., Bouffies, S., and Herman, M.: Inundation discriminated using sun glint, IEEE Transactions on Geoscience and Remote Sensing, 40, 1279-1287, 2002. 